\title{
El derecho de los adultos mayores a la seguridad social y la pensión de vejez reducida*
}

\section{The Right of Older Adults to Social Security and Reduced Old Age Pension}

\author{
Verónica Lidia Martínez Martínez ${ }^{* *}$
}

\section{RESUMEN}

Partiendo de los ordenamientos que fundamentan el derecho de los adultos mayores a la seguridad social en el sistema jurídico mexicano, asi como de la forma de acceder al seguro de vejez, en el presente trabajo se expone el incumplimiento al convenio (número 102) sobre la seguridad social (norma minima), ante la inexistencia de la pensión reducida de vejez en la Ley del Seguro Social. Fundamental fue el análisis de las disposiciones normativas nacionales e internacionales aplicables en el caso de México a los adultos mayores y, en especial, los ordenamientos que reglamentan el derecho a la pensión de vejez. Desde el punto de vista metodológico, la investigación requirió de la consulta de fuentes especializadas en Derecho Constitucional, Derecho Internacional de los Derechos Humanos y Seguridad Social, que, en comunión con los métodos analítico y deductivo, nos permitieron comprender el tipo de prestaciones que resultan procedentes en el seguro de vejez, los requisitos para acceder a ellas y la inobservancia al convenio número 102 como norma internacional de derechos humanos.

Palabras clave: pensión de vejez, pensión reducida, Organización Internacional del Trabajo, Instituto Mexicano del Seguro Social, convenio (número 102) sobre la seguridad social (norma minima).

\section{ABSTRACT}

Starting from the legal systems that support the right of older adults to social security in the Mexican legal system, as well as the way to access old-age insurance, in the present work, the breach of the Convention (number 102) social security (minimum norm) is exposed in the absence of the reduced old-age pension in the Social Security Law. Fundamental was the analysis of the national and international regulatory provisions applicable in the case of Mexico to the elderly and, especially, the regulations that regulate the right to an old-age pension. From the methodological point of view, the research required the consultation of specialized sources in constitutional law, international human rights law and social security, which in communion with the analytical and deductive methods, allowed us to understand the type of benefits that result from in old-age insurance, the requirements to access them and the non-observance of Convention No. 102 as an international human rights standard.

Keywords: old-age pension, reduced pension, International Labor Organization, Mexican Institute of Social Security, convention (number 102) on social security (minimum standard).

\footnotetext{
* Artículo de investigación recibido el 8 de enero de 2018 y aceptado para publicación el 16 de marzo de 2018.

** Profesora investigadora en la Universidad Anáhuac, Campus Norte de la Ciudad de México. (marb_cap@hotmail. com) orcid.org/0000-0002-7927-3006
} 
SUMARIO: 1. La seguridad social de los adultos mayores en el sistema jurídico mexicano / 2. La pensión de vejez en el régimen obligatorio del seguro social / 3. Incumplimiento de México a la regulación del seguro de vejez en el convenio (número 102) sobre la seguridad social (norma mínima) / 4. Conclusiones / 5. Referencias

Cuando se ha comprendido lo que es la condición de los viejos no es posible conformarse con reclamar una "política de la vejez" más generosa, una aumento de las pensiones, alojamientos sanos, ocios organizados. Todo el sistema es lo que está en juego y la reivindicación no puede sino ser radical: cambiar la vida.

Simone De BeAuvoIR

\section{La SEguridad SOCIAL de los adultos mayores EN El Sistema JURÍDICO MEXICANO}

En México, el corpus juris a través del cual se reconoce el derecho humano de los adultos mayores a acceder a la seguridad social se encuentra conformado, en primer lugar, por el 123, apartado A, fracción XXIX, de la Constitución Política de los Estados Unidos Mexicanos y su ordenamiento reglamentario, que se analiza en el siguiente apartado de esta obra.

Conforme a la precitada fracción del texto constitucional, se dispone que es de utilidad pública la Ley del Seguro Social, y ella comprenderá los seguros de invalidez, de vejez, de vida, de cesación involuntaria del trabajo, de enfermedades y accidentes, de servicios de guardería y cualquier otro encaminado a la protección y bienestar de los trabajadores, campesinos, no asalariados y otros sectores sociales y sus familiares. ${ }^{1}$

Además de que México cuenta en cada una de las entidades federativas con una legislación de protección de los derechos de las personas mayores, a nivel federal, la Ley de los Derechos de las Personas Adultas Mayores consigna la obligación del Estado de garantizarles las condiciones óptimas de

\footnotetext{
${ }^{1}$ Artículo 123, apartado A, fracción XXIX, de la Constitución Politica de los Estados Unidos Mexicanos [Consulta: 29 de diciembre de 2017]. Disponible en: http://www.diputados.gob.mx/LeyesBiblio/pdf/1_150917.pdf.
} 
salud, educación, nutrición, vivienda, desarrollo integral y seguridad social. ${ }^{2}$ De acuerdo con este mismo ordenamiento, es objetivo de la política pública nacional sobre adultos mayores fomentar que las instituciones educativas y de seguridad social establezcan las disciplinas para la formación en geriatría y gerontología, con el fin de garantizar la cobertura de los servicios de salud requeridos por la población adulta mayor. ${ }^{3}$

Asimismo, el artículo 25.1 de la Declaración Universal de los Derechos Humanos ${ }^{4}$ consigna el derecho de toda persona a un nivel de vida adecuado que le asegure, así como a su familia, la salud y el bienestar, y en especial la alimentación, el vestido, la vivienda, la asistencia médica y los servicios sociales necesarios, además del derecho a los seguros en caso de desempleo, enfermedad, invalidez, viudez, vejez u otros casos de pérdida de sus medios de subsistencia por circunstancias independientes de su voluntad. ${ }^{5}$

En términos generales, el artículo 9 del Pacto Internacional de Derechos Económicos, Sociales y Culturales dispone que los Estados partes reconocen el derecho de toda persona a la seguridad social, incluso al seguro social, ${ }^{6}$ en el que de forma implícita se reconoce el derecho a las prestaciones de vejez.

En tanto que en el artículo 11, numeral 1, inciso e), de la Convención sobre la Eliminación de todas las Formas de Discriminación contra la Mujer se consigna la obligación de los Estados partes de adoptar todas las medidas apropiadas para eliminar la discriminación contra la mujer en la esfera del empleo, a fin de asegurar a la mujer, en condiciones de igualdad con los hombres, los mismos derechos, en particular el derecho a la seguridad social, en casos de jubilación, desempleo, enfermedad, invalidez, vejez u otra incapacidad para trabajar, así como el derecho a vacaciones pagadas. ${ }^{7}$

\footnotetext{
${ }^{2}$ Artículo 6 de la Ley de los Derechos de las Personas Adultas Mayores [Consulta: 24 de noviembre de 2017]. Disponible en: http://www.salud.gob.mx/unidades/cdi/nom/compi/ldpam.html.

${ }^{3}$ Idem. Artículo 10 de la Ley de los Derechos de las Personas Adultas Mayores [Consulta: 29 de abril de 2017]. Disponible en: http://www.salud.gob.mx/unidades/cdi/nom/compi/ldpam.html.

${ }^{4}$ De acuerdo con el artículo 2 de la Proclamación de Teherán, la Declaración Universal de Derechos Humanos enuncia una concepción común a todos los pueblos de los derechos iguales e inalienables de todos los miembros de la familia humana y la declara obligatoria para la comunidad internacional. Vid Proclamación de Teherán. Adopción: Conferencia Internacional de Derechos Humanos, Teherán, Irán, 13 de mayo de 1968 [Consulta: 26 de octubre de 2017]. Disponible en: http://www.ordenjuridico.gob.mx/TratInt/Derechos\%20Humanos/0TROS\%2016.pdf.

${ }^{5}$ Declaración Universal de Derechos Humanos [Consulta: 29 de septiembre de 2017]. Disponible en: http://www. ordenjuridico.gob.mx/TratInt/Derechos\%20Humanos/INST\%2000.pdf.

${ }^{6}$ Artículo 9 del Pacto Internacional de Derechos Económicos, Sociales y Culturales [Consulta: 29 de octubre de 2017]. Disponible en: http://www.ohchr.org/SP/Professionallnterest/Pages/CESCR.aspx.

${ }^{7}$ Artículo 11, numeral 1, inciso e), de la Convención sobre la Eliminación de todas las Formas de Discriminación contra la Mujer [Consulta: 21 de octubre de 2017]. Disponible en: http://www.ohchr.org/SP/Professionallnterest/ Pages/CEDAW.aspx.
} 
En el Sistema Interamericano de Derechos Humanos, el artículo XVI de la Declaración Americana de los Derechos y Deberes del Hombre ${ }^{8}$ dispone que toda persona tiene derecho a la seguridad social que le proteja contra las consecuencias de la desocupación, de la vejez y de la incapacidad, que, proveniente de cualquier otra causa ajena a su voluntad, la imposibilite física o mentalmente para obtener los medios de subsistencia. ${ }^{9}$

De manera más específica, los artículos 9.1 y 17 del Protocolo Adicional a la Convención Americana sobre Derechos Humanos en materia de Derechos Económicos, Sociales y Culturales, textualmente rezan: ${ }^{10}$

Artículo 9. Derecho a la seguridad social

1. Toda persona tiene derecho a la seguridad social que la proteja contra las consecuencias de la vejez y de la incapacidad que la imposibilite física o mentalmente para obtener los medios para llevar una vida digna y decorosa. En caso de muerte del beneficiario las prestaciones de seguridad social serán aplicadas a sus dependientes.

Artículo 17 Protección de los ancianos

Toda persona tiene derecho a protección especial durante su ancianidad. En tal cometido, los Estados Partes se comprometen a adoptar de manera progresiva las medidas necesarias a fin de llevar este derecho a la práctica y en particular a:

a. Proporcionar instalaciones adecuadas, así como alimentación y atención médica especializada a las personas de edad avanzada que carezcan de ella y no se encuentren en condiciones de proporcionársela por sí mismas; b. Ejecutar programas laborales específicos destinados a conceder a los ancianos la posibilidad de realizar una actividad productiva adecuada a sus capacidades respetando su vocación o deseos; c. Estimular la formación de organizaciones sociales destinadas a mejorar la calidad de vida de los ancianos.

\footnotetext{
${ }^{8}$ El carácter obligatorio de la Declaración Americana de los Derechos y Deberes del Hombre fue decretada en la Resolución 23/81, Caso Estados Unidos, párrafos 15-16 [Consulta: 21 de diciembre de 2017]. Disponible en: https:// www.cidh.oas.org/annualrep/80.81sp/Estados Unidos2141a.htm.

${ }_{9}^{9}$ Artículo XVI de la Declaración Americana de los Derechos y Deberes del Hombre [Consulta: 31 de diciembre de 2018]. Disponible en: https://www.oas.org/dil/esp/Declaraci\%C3\%B3n_Americana_de_los_Derechos_y_Deberes_del_Hombre_1948.pdf.

${ }^{10}$ Artículos 9.1 y 17 del Protocolo Adicional a la Convención Americana sobre Derechos Humanos en materia de Derechos Económicos, Sociales y Culturales [Consulta: 2 de enero de 2018]. Disponible en: http://www.ordenjuridico.gob.mx/TratInt/Derechos\%20Humanos/PI2.pdf.
} 
Por su parte, en el seno de la Organización de los Estados Americanos, la Convención Interamericana sobre la Protección de los Derechos Humanos de las Personas Mayores, a pesar de que fue adoptada en Washington el 15 de junio de 2015, entrará en vigor el trigésimo día a partir de la fecha en que se haya depositado el segundo instrumento de ratificación.

El objeto de esta Convención es promover, proteger y asegurar el reconocimiento y el pleno goce y ejercicio, en condiciones de igualdad, de todos los derechos humanos y libertades fundamentales de la persona mayor, a fin de contribuir a su plena inclusión, integración y participación en la sociedad.

Dentro de los derechos que se reconocen a los adultos mayores se encuentran el derecho a la igualdad y no discriminación por razones de edad, el derecho a la vida y a vivir con dignidad en la vejez, el derecho a la independencia y autonomía, el derecho a la participación e integración en la comunidad, el derecho a la seguridad y a una vida libre de violencia, el derecho a no ser sometido a tortura ni a penas o tratos crueles, inhumanos o degradantes; el derecho a la recreación, al esparcimiento y al deporte; los derechos de reunión y asociación, así como los derechos políticos, por mencionar algunos. Al día de hoy, sólo Argentina, Brasil, Chile, Costa Rica y Uruguay han suscrito la Convención. México se encuentra en proceso de ratificar este instrumento.

A lo anterior se adicionan los instrumentos de soft law que consignan el derecho de los adultos mayores a la seguridad social. En el plano regional de las Naciones Unidas se encuentran el Plan de Acción Internacional de Viena sobre el Envejecimiento, de 1982; la Declaración Política y el Plan de Acción Internacional de Madrid sobre el Envejecimiento, así como la Declaración sobre el Progreso y el Desarrollo en lo Social, proclamada por la Asamblea General de las Naciones Unidas en su resolución 2542 (XXIV), del 11 de diciembre de 1969, en la que se provee la provisión de sistemas amplios de seguridad social y la mejora de los sistemas de seguros sociales para todas aquellas personas que por enfermedad, invalidez o vejez no pueden ganarse la vida, temporal o permanentemente. ${ }^{11}$

En las resoluciones 1405 (XLVI) y 1406 (XLVI), del 5 de junio de 1969, así como en la resolución 1751 (LIV), del 16 de mayo de 1973, del Consejo Económico y Social, se ha reconocido el derecho de los adultos mayores a la seguridad social. Dentro de las resoluciones de la Asamblea General de la ONU, referentes al derecho de la seguridad social de la población adulta mayor, se

${ }^{11}$ Declaración sobre el Progreso y el Desarrollo en lo Social [Consulta: 2 de enero de 2018]. Disponible en: http:// www.ohchr.org/SP/Professionallnterest/Pages/ProgressAndDevelopment.aspx. 
encuentran la resolución 32/131, del 16 de diciembre de 1977, y la resolución 3137 (XXVIII), del 14 de diciembre de 1973; ambas resoluciones, referentes a la "Cuestión de las personas de edad y los ancianos", consignan la necesidad de desarrollar progresivamente medidas de seguridad social para garantizar que los ancianos, sea cual fuere su sexo, reciban ingresos adecuados. El otro instrumento que destaca por su importancia es la resolución 3138 (XXVIII), del 14 de diciembre de 1973, sobre la "Seguridad social para los ancianos". Igualmente, en el seno del Comité de Derechos Económicos, Sociales y Culturales de la $0 \mathrm{NU}$, las observaciones generales números 6, 19 y 20 consignan el derecho de los adultos mayores a la seguridad social.

En lo concerniente a la normatividad de la Organización Internacional del Trabajo (оIт), tenemos que en el preámbulo de la Constitución de la oIT, las Altas Partes Contratantes, movidas por sentimientos de justicia y de humanidad y por el deseo de asegurar la paz permanente en el mundo, adoptaron este instrumento, al considerarse que existen condiciones de trabajo que entrañan tal grado de injusticia, miseria y privaciones para gran número de seres humanos; dentro de esas condiciones, es urgente mejorar el texto constitucional de la orT, señala las pensiones de vejez. ${ }^{12}$

Por su parte, la recomendación sobre los trabajadores de edad (número 162), adoptada el 23 de junio de 1980 en la 66 Reunión de la Conferencia Internacional del Trabajo, establece la aplicación de un programa que permita a los trabajadores prever las disposiciones necesarias, con el fin de preparar su jubilación y adaptarse a su nueva situación, proporcionándoles información apropiada. Según el texto de la recomendación, debe ofrecerse información al trabajador de edad mayor sobre los temas siguientes: ${ }^{13}$

- Ingresos y prestaciones de vejez a los que pueda tener derecho

- Posibilidad de continuar la actividad profesional, especialmente a tiempo parcial, como también de constituirse en trabajador por cuenta propia

- Envejecimiento individual y cómo prevenirlo

- Utilización del tiempo libre

\footnotetext{
${ }_{12}$ Preámbulo de la Constitución de la Organización Internacional del Trabajo [Consulta: 6 de enero de 2017]. Disponible en: http://www.ilo.org/dyn/normlex/es/f?p=1000:62:0::NO:62:P62_LIST_ENTRIE_ID:2453907:NO\#A14. ${ }^{13}$ Recomendación sobre los trabajadores de edad (número 162) [Consulta: 6 de enero de 2017]. Disponible en: http://www.ilo.org/dyn/normlex/es/f?p= NORMLEXPUB:12100:0:: NO::P12100_ILO_CODE:R162.
} 
- Facilidades disponibles para la educación del adulto, bien sea para responder a los problemas específicos de la jubilación, o mantener sus esferas de interés

En tanto, la resolución relativa a la seguridad social de la oIT hace un llamado especial a considerar las repercusiones que impone el envejecimiento de la población a la seguridad social, tanto en los sistemas de capitalización como en los de reparto, proponiendo que las soluciones atinentes a la transferencia intergeneracional deben centrarse en medidas destinadas a aumentar las tasas de empleo, en particular de las mujeres, los trabajadores de edad avanzada, los jóvenes y los discapacitados. ${ }^{14}$

La resolución relativa a la seguridad social -en concordancia con lo establecido en la Declaración Universal de Derechos Humanos y el Pacto de Derechos Económicos, Sociales y Culturales- recalca que la seguridad social es un derecho fundamental y un instrumento esencial para crear cohesión social y, de ese modo, garantizar la integración social. ${ }^{15}$

En el caso de México, ante su carácter vinculante, el convenio (número 102) sobre la seguridad social (norma mínima) regula de una forma más especializada la rama de vejez. El análisis de este instrumento normativo se trata en el tercer apartado del presente trabajo.

Finalmente, en la comunidad de Iberoamérica destaca el Programa Iberoamericano de Cooperación sobre Adultos Mayores en la Región, ${ }^{16}$ aprobado en 2011 por la XXI Cumbre Iberoamericana de Jefes de Estado y de Gobierno, cuya unidad técnica ha sido asumida por la Organización Iberoamericana de Seguridad Social, teniendo como área temática la seguridad social y los servicios sociales de los adultos mayores.

\section{La pensión de Vejez en el RÉgimen Obligatorio del SEguro social}

De acuerdo con la actual Ley del Seguro Social, para que el asegurado tenga derecho al goce de las prestaciones del seguro de vejez, debe cumplir con los siguientes requisitos:

\footnotetext{
${ }^{14}$ Resolución relativa a la seguridad social [Consulta: 6 de enero de 2017]. Disponible en: http://white.lim.ilo.org/ ssos/documentos/seguridadsocial-un-nuevo-consenso.pdf.

${ }^{15}$ Idem.

${ }^{16}$ Hasta la fecha, los paises adheridos al Programa Iberoamericano de Cooperación sobre Adultos Mayores en la Región son Argentina, Brasil, Chile, Ecuador, España, México, Paraguay y Uruguay.
} 
- Haber cumplido sesenta y cinco años de edad. ${ }^{17}$

- Tener reconocidas por el Instituto Mexicano del Seguro Social un mínimo de mil doscientas cincuenta cotizaciones semanales (veinticinco años de cotizar al régimen obligatorio del seguro social). ${ }^{18}$

- Haber quedado privado de trabajo remunerado. ${ }^{19}$

- Estar en conservación de derechos. ${ }^{20}$

- Solicitar la pensión de vejez ante el Instituto Mexicano del Seguro Social. ${ }^{21}$

Ante la negativa de otorgamiento de la pensión, es posible que el otorgamiento y pago de las prestaciones del seguro de vejez deriven de un laudo dictado por la Junta Especial de la Federal de Conciliación y Arbitraje del lugar en el que se encuentre la clínica del Instituto Mexicano del Seguro Social a la cual se encuentren adscritos los asegurados o sus beneficiarios.

De existir controversia sobre el número de semanas cotizadas en los ramos de aseguramiento y la vigencia de derechos, ${ }^{22}$ la carga de la prueba recae

\footnotetext{
${ }^{17}$ Artículo 162 de la actual Ley del Seguro Social [Consulta: 1 de enero de 2018]. Disponible en: http://www.diputados.gob.mx/LeyesBiblio/pdf/92_121115.pdf.

${ }_{18}$ Idem.

${ }^{19}$ Idem. Artículo 163 de la actual Ley del Seguro Social.

${ }^{20}$ Idem. Artículos 150 y 151 de la actual Ley del Seguro Social. El periodo de conservación de derechos es lapso para acceder a las prestaciones de seguridad social previstas en la Ley del Seguro Social y sus disposiciones reglamentarias.

${ }^{21}$ Idem. Artículo 163 de la actual Ley del Seguro Social.

${ }^{22}$ Artículo 899-D de la Ley Federal del Trabajo [Consulta: 1 de enero de 2018]. Disponible en: http://www.diputados. gob.mx/LeyesBiblio/pdf/125_120615.pdf. Así mismo, las siguientes tesis: Tesis: 2a./J. 27/98, Novena Época, Segunda Sala, Semanario Judicial de la Federación y su Gaceta, Tomo VII, Mayo de 1998, Página: 524, SEGURO SOCIAL. LA CARGA DE LA PRUEBA DE LAS COTIZACIONES DE LOS TRABAJADORES QUE SIRVEN DE BASE SALARIAL PARA DETERMINAR LA CUANTIFICACIÓN DE LAS PENSIONES QUE PREVÉ LA LEY RELATIVA, CORRESPONDE AL INSTITUTO MEXICANO DEL SEGURO SOCIAL [Consulta: 30 de diciembre de 2017]. Disponible en: http://200.38.163.178/ sjfsist/Paginas/DetalleGeneralV2.aspx? Epoca $=100210000000000 \&$ Apendice $=1000000000000 \&$ Expresion $=$ SE GUR0\%2520SOCIAL.\%2520LA\%2520CARGA\%2520DE\%2520LA\%2520PRUEBA\%2520DE\%2520LAS\%2520C OTIZACIONES\%2520\&Dominio $=$ Rubro,Texto\&TA_TJ $=2 \&$ Crden $=1 \&$ Clase $=$ DetalleTesisBL\&NumTE $=10 \& E p p=20$ $\&$ tDesde $=100 \&$ Hasta $=-100 \&$ Index $=0 \&$ InstanciasSeleccionadas $=2,7 \& \mid \mathrm{ID}=197601 \& \mathrm{H}$ Hit $=9 \& \mid \mathrm{IDs}=170283,170887$, $171684,179519,184290,188946,195730,196394,197601,198594 \& t$ tipoTesis=\&Semanario=0\&tabla=\&tReferencia $=$ \&Tema=. Tesis: XIX.20.P.T.2 L (10a.). Semanario Judicial de la Federación y su Gaceta. Décima Época. Tribunales Colegiados de Circuito. Libro XVIII, Marzo de 2013, Tomo 3. Página 2048, bajo el rubro: PENSIÓN POR CESANTÍA EN EDAD AVANZADA. PARA CUANTIFICARLA CORRESPONDE AL INSTITUTO MEXICANO DEL SEGURO SOCIAL LA CARGA DE LA PRUEBA DEL PROMEDIO SALARIAL DE LAS ÚLTIMAS 250 SEMANAS DE COTIZACIÓN, AL CONTAR CON MÁS Y MEJORES ELEMENTOS DE PRUEBA QUE EL ASEGURADO [Consulta: 30 de diciembre de 2017]. Disponible en: http://200.38.163.178/sjfsist/Paginas/DetalleGeneral V2.aspx?Epoca $=1$ e3210000000000\&Apendice $=1000000$ 000000\&tExpresion=PENSI\%25C3\%2593N\%2520POR\%2520CESANT\%25C3\%258DA\%2520EN\%2520EDAD\%25 20AVANZADA.\%2520PARA\%2520CUANTIFICARLA\%2520CORRESPONDE\%2520AL\%2520INSTITUT0\%2520MEXI CANO\%2520DEL \%2520SEGUR0\%2520S0CIAL\%2520LA\%2520CARGA\%2520DE\%2520LA\%2520PRUEBA\%2520 DEL\%2520PROMEDI0\%2520\&Dominio=Rubro,Texto\&TA_TJ=2\&Orden $=1 \&$ Clase $=$ DetalleTesisBL\&NumTE $=1 \&$ Epp $=20 \&$ Desde $=-100 \&$ Hasta $=-100 \& \mid$ Index $=0 \& \mid$ nstanciasSeleccionadas $=6,1,2,50,7 \& \mid \mathrm{D}=2003100 \& \mathrm{Hit}=1 \& \mathrm{tDs}=200310$ $0 \&$ ttipoTesis $=\&$ tSemanario $=0 \&$ ttabla $=\&$ tReferencia $=\&$ t. Tema $=$ Tesis: IV.40.5 L, Novena Época. Instancia: Tribunales
} 
de manera directa en el Instituto Mexicano del Seguro Social al contar con más y mejores elementos de prueba que el asegurado, pues, en su calidad de organismo asegurador, es a quien le corresponde conservar los comprobantes e información idónea para acreditar el tiempo de cotización por tener a su cargo el registro e inscripción de los trabajadores para efectos del seguro social obligatorio, altas y bajas de estos, así como el registro de los salarios y sus modificaciones. ${ }^{23}$

El asegurado - que ha cubierto los anteriores requisitos- tendrá derecho en su carácter de pensionado por vejez, al otorgamiento de las prestaciones en especie del seguro de enfermedades y maternidad, así como al pago de las prestaciones en dinero que dependerán del saldo que haya acumulado en la cuenta individual.

Los recursos de su cuenta individual podrán ser utilizados por el asegurado para contratar el seguro de renta vitalicia o efectuar retiros programados. La renta vitalicia se contrata con una aseguradora que, al recibir los recursos acumulados en la cuenta individual, establecerá el seguro de sobrevivencia en favor de los beneficiarios del asegurado, ${ }^{24}$ y determinará el monto de la pensión de vejez que cubrirá de manera mensual durante la vida del pensionado.

El monto de la pensión dependerá de los fondos acumulados en la cuenta individual y el estimado de vida del derechohabiente al momento del retiro realizado por la compañía aseguradora. La renta vitalicia se actualizará anualmente en el mes de febrero conforme al Índice Nacional de Precios al Consumidor.

En la forma de retiro programado, el asegurado contratará directamente con la Administradora de Fondos para el Retiro (Afore), para que le cubra la

\footnotetext{
Colegiados de Circuito. Semanario Judicial de la Federación y su Gaceta. Tomo VI, Octubre de 1997, Página: 756, bajo el rubro: INVALIDEZ, PENSIÓN DE. CARGA DE LA PRUEBA DE LOS REQUISITOS RELATIVOS AL NÚMERO DE COTIZACIONES SEMANALES PAGADAS AL INSTITUTO MEXICANO DEL SEGURO SOCIAL Y A LA CONSERVACIÓN DE DERECHOS, CONTEMPLADAS POR LOS ARTÍCULOS 131 Y 182 DE LA LEY DEL SEGURO SOCIAL [Consulta: 30 de diciembre de 2017]. Disponible en: http:// 00.38.163.178/sjfsist/Paginas/DetalleGeneralV2.aspx?Epoca=100a1000 0000000\&Apendice $=1000000000000 \&$ Expresion $=$ INVALIDEZ\%2C\%2520PENSI\%25C3\%2593N\%2520DE. $\% 2520 \mathrm{C}$ ARGA\%2520DE\%2520LA\%2520PRUEBA\%2520\&Dominio=Rubro,Texto\&TA_TJ=2\&tOrden=1\&Clase=DetalleTesisB L\&NumTE $=5 \& E p p=20 \&$ Desde $=-100 \&$ Hasta $=-100 \& \mid$ Index $=0 \&$ InstanciasSeleccionadas $=6,2,7 \&|\mathrm{D}=197601 \& \mathrm{Hit}=5 \& \mathrm{t}|$ Ds $=165975,179519,185147,189571,197601 \&$ ttipoTesis $=\&$ Semanario $=0$ \&tabla $=$ \&tReferencia $=\&$ Tema $=$.

${ }^{23}$ Artículos 251 de la Ley del Seguro Social, op. cit., nota 17, en correlación con los artículos 47, 50, 55, 57, 112, 122 del Reglamento de la Ley del Seguro Social en materia de afiliación, clasificación de empresas, recaudación y fiscalización [Consulta: 29 de abril de 2014]. Disponible en: http://www.diputados.gob.mx/LeyesBiblio/regley/ Reg_LSS_MACERF.pdf.

${ }^{24}$ Con el seguro de sobrevivencia se otorga a los beneficiarios del pensionado la pensión, ayudas asistenciales y demás prestaciones en dinero previstas en el seguro de vejez, mediante la renta que se les asignará después del fallecimiento del pensionado hasta la extinción legal de las pensiones.
} 
pensión de vejez. Bajo esta modalidad se obtendrá una pensión al fraccionar el monto total de los recursos de la cuenta individual y tomar en cuenta la esperanza de vida de los pensionados, así como los rendimientos previsibles de los saldos.

Para efectos del retiro programado, se calculará cada año una anualidad que será igual al resultado de dividir el saldo de su cuenta individual entre el capital necesario para financiar una unidad de renta vitalicia ${ }^{25}$ para el asegurado y sus beneficiarios, por lo menos igual al valor correspondiente a la pensión garantizada. La pensión mensual corresponderá a la doceava parte de dicha anualidad. Al igual que en el seguro de renta vitalicia, al saldo de la cuenta individual se le descuenta la cantidad necesaria para contratar el seguro de sobrevivencia que protegerá a los beneficiarios del pensionado.

Los fondos acumulados en la subcuenta de aportaciones voluntarias, aportaciones complementarias para el retiro o aportaciones voluntarias a largo plazo podrán formar parte del saldo para la determinación de los pagos de los retiros programados. En caso de fallecimiento del pensionado, sólo bajo la modalidad de retiro programado, los fondos restantes podrán ser reclamados por el beneficiario. De agotarse los recursos de la cuenta individual, se cubrirá al pensionado una pensión mínima garantizada $(P M G)$ con los recursos proporcionados por el Gobierno.

A pesar de haber optado por la modalidad de retiros programados, en cualquier momento el pensionado podrá contratar una renta vitalicia. El pensionado no podrá efectuar el cambio de modalidad cuando la renta mensual vitalicia sea inferior a la pensión garantizada.

En caso de que el asegurado cubra los requisitos para acceder a la pensión de vejez pero en su cuenta individual no existan los recursos suficientes para contratar un retiro programado o renta vitalicia junto con el seguro de sobrevivencia, el Instituto Mexicano del Seguro Social cubrirá una pensión mínima garantizada. La pensión mínima garantizada es equivalente a un salario mínimo vigente en el Distrito Federal al mes, siendo actualizada anualmente conforme al Índice Nacional de Precios al Consumidor.

Además de la pensión de vejez, el pensionado percibirá el pago de las asignaciones familiares o ayudas asistenciales. Ambas prestaciones, al consistir en una ayuda por carga familiar, se concederán de acuerdo con las reglas siguientes:

${ }^{25}$ Las tablas utilizadas para calcular la unidad de renta vitalicia se elaborarán anualmente por la Comisión Nacional de Seguros y Fianzas. 
Cuadro 1. Asignaciones familiares y ayudas asistenciales.

\begin{tabular}{|c|c|c|c|}
\hline Prestación & Grupo protegido & Requisitos & $\begin{array}{l}\text { Monto de la cuan- } \\
\text { tía de la pensión } \\
\text { de vejez }\end{array}$ \\
\hline $\begin{array}{l}\text { Asignación fami- } \\
\text { liar por esposa } 0 \\
\text { concubina }\end{array}$ & $\begin{array}{c}\text { Esposa } \\
\text { Concubina }\end{array}$ & $\begin{array}{l}\text {-- Acta de matrimonio. } \\
\text {--Haber vivido con el pensionado durante } \\
\text { los cinco años que precedieron inmedia- } \\
\text { tamente a su muerte. La existencia de } \\
\text { este requisito no opera en caso de existir } \\
\text { un descendiente. } \\
\text {-- Que el pensionado y la concubina } \\
\text { hubieran permanecido libres de matri- } \\
\text { monio durante el concubinato. }\end{array}$ & $15 \%$ \\
\hline $\begin{array}{l}\text { Asignación fami- } \\
\text { liar por hijos }\end{array}$ & Hijos & $\begin{array}{l}\text { - Acta de nacimiento. } \\
\text { - Menores de dieciséis años. } \\
\text { - De } 16 \text { a } 25 \text { años, si se encuentra } \\
\text { estudiando en planteles del sistema } \\
\text { educativo nacional, tomando en consi- } \\
\text { deración las condiciones económicas, } \\
\text { familiares y personales del beneficiario, } \\
\text { siempre que no sea sujeto del régimen } \\
\text { obligatorio. } \\
\text { - No pueda mantenerse por su propio } \\
\text { trabajo debido a una enfermedad cróni- } \\
\text { ca, defecto físico o psíquico, en tanto no } \\
\text { desaparezca la incapacidad. }\end{array}$ & $10 \%$ para cada hijo \\
\hline $\begin{array}{l}\text { Asignación fami- } \\
\text { liar por padres }\end{array}$ & Madre y padre & $\begin{array}{l}\text {-- Dependencia económica. } \\
\text { - No tener esposa o concubina ni hijos } \\
\text { menores de dieciséis años. }\end{array}$ & $\begin{array}{l}10 \% \text { para cada } \\
\text { padre }\end{array}$ \\
\hline $\begin{array}{l}\text { Ayuda asistencial } \\
\text { por soledad }\end{array}$ & Pensionado & $\begin{array}{l}\text { No tener esposa o concubina ni hijos ni } \\
\text { ascendientes que dependan económica- } \\
\text { mente del pensionado. }\end{array}$ & $15 \%$ \\
\hline Ayuda asistencial & Ascendiente & Tener un solo ascendiente. & $10 \%$ \\
\hline Ayuda asistencial & Pensionado & $\begin{array}{l}\text {-- Estado físico que requiera ineludible- } \\
\text { mente, que lo asista otra persona de } \\
\text { manera permanente o continua. } \\
\text {-- Dictamen médico que certifique el } \\
\text { estado físico del pensionado. }\end{array}$ & $20 \%$ \\
\hline
\end{tabular}

Fuente: Elaboración propia con base en los artículos 134, 138 y 140 de la Ley del Seguro Social en vigor.

Como puede advertirse en contravención al principio de igualdad de trato entre hombres y mujeres en materia de seguridad social y a la prohibición de discriminación, no se contempla en la actual Ley del Seguro Social el pago de las asignaciones familiares en favor del esposo o concubinario de la 
asegurada, lo cual contraviene lo dispuesto en los artículos 1 y 4 de la Constitución mexicana.

Asimismo, la falta de pago de las asignaciones familiares para la asegurada o pensionada transgrede los tratados internacionales suscritos por México, que contemplan el derecho de igualdad y el principio-obligación básico de no discriminación, dentro de los cuales se encuentran el artículo II de la Declaración Americana de los Derechos y Deberes del Hombre; los artículos 1, 2, 7 y 23 de la Declaración Universal de Derechos Humanos; el artículo 55 de la Carta de la Organización de Naciones Unidas; los artículos 1 y 24 de la Convención Americana sobre Derechos Humanos; los artículos 2, 3 y 7 del Pacto Internacional de Derechos Económicos, Sociales y Culturales; así como los artículos 2, 3, 20.2, 24 y 26 del Pacto Internacional de Derechos Civiles y Políticos.

La cuota social que aporte el Estado en la cuenta individual para los asegurados que ganen hasta quince veces el salario mínimo general vigente en el Distrito Federal es empleada para financiar las asignaciones familiares y las ayudas asistenciales. Para los trabajadores que no reciban cuota social en sus cuentas individuales, las asignaciones familiares y las ayudas asistenciales se financiarán con las aportaciones patronales y del Estado que se realicen a la subcuenta de retiro, cesantía en edad avanzada y vejez.

Las asignaciones familiares y las ayudas asistenciales cesarán con la muerte del familiar que las originó y se entregarán de preferencia al propio pensionado, pero la correspondiente a los hijos podrá entregarse a la persona o institución que los tenga bajo su cargo directo, en el caso de no vivir con el pensionado.

\section{Incumplimiento de MÉxico a la regulación del seguro de Vejez en

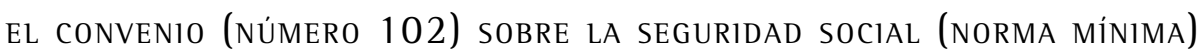

En México, a consecuencia de la reforma realizada el 10 de junio de 2011 al artículo 1 constitucional, se amplió el contenido material de los derechos humanos al reconocerse no sólo los previstos en la Constitución, sino también los establecidos en los tratados internacionales de los que México sea parte por disposición expresa de los artículos 1, 15, 103, 105, 107 constitucionales.

Así, los derechos consagrados en el derecho internacional de los derechos humanos se han transformado en derechos humanos nacionales de fuente 
internacional con todas sus consecuencias, ${ }^{26}$ lo que, en palabras de Ferrer Mac-Gregor, representa una constitucionalización del derecho internacional ${ }^{27}$ que provoca la complementariedad de la supremacía constitucional y la primacía del derecho internacional, evitando así la competencia, controversia y jerarquía entre el derecho nacional y el derecho internacional.

Una de las principales polémicas ha sido determinar la posición que ocupan los tratados internacionales dentro del sistema jurídico mexicano. A principios de la década de los noventa, la Suprema Corte de Justicia de la Nación consideró que las leyes federales y los tratados internacionales se encuentran en el mismo nivel jerárquico. ${ }^{28}$ Sin embargo, ese criterio fue abandonado por el Pleno de la Corte al resolver, el 11 de mayo de 1999, el amparo en revisión 1475/98, promovido por el Sindicato Nacional de Controladores de Tránsito Aéreo, sosteniendo en dicho asunto que los tratados internacionales están en una jerarquía superior sobre el derecho federal y el local, salvo que la Constitución general de la República señale algún caso especial.

\footnotetext{
${ }^{26}$ Fix-Zamudio, Héctor, "Las repercusiones en los ámbitos interno e internacional de la reforma constitucional mexicana sobre derechos humanos del 10 de junio de 2011", en Serna de la Garza, José Ma. (coord.), Contribuciones al derecho constitucional, UNAM-Instituto de Investigaciones Jurídicas, México, 2016, pp. 26-27.

${ }^{27}$ Ferrer Mac-Gregor, Eduardo, "Interpretación conforme y control difuso de convencionalidad. El nuevo paradigma para el juez mexicano", Estudios Constitucionales, año 9, núm. 2, 2011, pp. 546-547.

${ }^{28}$ Octava Época. Instancia: Pleno. Fuente: Gaceta del Semanario Judicial de la Federación. Número 60, Diciembre de 1992. Materia(s): Constitucional. Tesis: P. C/92. Página: 27, bajo el rubro: LEYES FEDERALES Y TRATADOS INTERNACIONALES. TIENEN LA MISMA JERARQUIA NORMATIVA. De conformidad con el artículo 133 de la Constitución, tanto las leyes que emanen de ella, como los tratados internacionales, celebrados por el ejecutivo Federal, aprobados por el Senado de la República y que estén de acuerdo con la misma, ocupan, ambos, el rango inmediatamente inferior a la Constitución en la jerarquía de las normas en el orden jurídico mexicano. Ahora bien, teniendo la misma jerarquia, el tratado internacional no puede ser criterio para determinar la constitucionalidad de una ley ni viceversa. Por ello, la Ley de las Cámaras de Comercio y de las de Industria no puede ser considerada inconstitucional por contrariar lo dispuesto en un tratado internacional [Consulta: 29 de octubre de 2017]. Disponible en: https://sjf.scjn.gob.mx/SJFSist/paginas/DetalleGeneralV2.aspx?id=205596\&Clase=DetalleTesisB.
} 


\section{Asimismo, el Pleno del Alto Tribunal -en la sesión privada celebrada} el veintiocho de octubre de 1999- aprobó la tesis P. LXXVII/99, en la que determinó la jerarquía supralegal e infraconstitucional de los tratados internacionales. ${ }^{29}$

En 2007, el Pleno de la Corte, al realizar la interpretación del artículo 133 constitucional, reiteró que los tratados internacionales son parte integrante de la ley suprema de la Unión y que se ubican jerárquicamente por encima de las leyes generales, federales y locales. ${ }^{30}$ Lo anterior evidencia que la Corte

\footnotetext{
${ }^{29}$ Novena Época. Instancia: Pleno. Fuente: Semanario Judicial de la Federación y su Gaceta. Tomo X, Noviembre de 1999. Tesis: P. LXXVII/99. Página: 46, bajo el rubro: TRATADOS INTERNACIONALES. SE UBICAN JERÁRQUICAMENTE POR ENCIMA DE LAS LEYES FEDERALES Y EN UN SEGUNDO PLANO RESPECTO DE LA CONSTITUCIÓN FEDERAL. Persistentemente en la doctrina se ha formulado la interrogante respecto a la jerarquia de normas en nuestro derecho. Existe unanimidad respecto de que la Constitución Federal es la norma fundamental y que aunque en principio la expresión "... serán la Ley Suprema de toda la Unión ..." parece indicar que no sólo la Carta Magna es la suprema, la objeción es superada por el hecho de que las leyes deben emanar de la Constitución y ser aprobadas por un órgano constituido, como lo es el Congreso de la Unión y de que los tratados deben estar de acuerdo con la Ley Fundamental, lo que claramente indica que sólo la Constitución es la Ley Suprema. El problema respecto a la jerarquía de las demás normas del sistema, ha encontrado en la jurisprudencia y en la doctrina distintas soluciones, entre las que destacan: supremacía del derecho federal frente al local y misma jerarquía de los dos, en sus variantes lisa y llana, y con la existencia de "leyes constitucionales", y la de que será ley suprema la que sea calificada de constitucional. No obstante, esta Suprema Corte de Justicia considera que los tratados internacionales se encuentran en un segundo plano inmediatamente debajo de la Ley Fundamental y por encima del derecho federal y el local. Esta interpretación del artículo 133 constitucional, deriva de que estos compromisos internacionales son asumidos por el Estado mexicano en su conjunto y comprometen a todas sus autoridades frente a la comunidad internacional; por ello se explica que el Constituyente haya facultado al presidente de la República a suscribir los tratados internacionales en su calidad de jefe de Estado y, de la misma manera, el Senado interviene como representante de la voluntad de las entidades federativas y, por medio de su ratificación, obliga a sus autoridades. Otro aspecto importante para considerar esta jerarquia de los tratados, es la relativa a que en esta materia no existe limitación competencial entre la Federación y las entidades federativas, esto es, no se toma en cuenta la competencia federal o local del contenido del tratado, sino que por mandato expreso del propio artículo 133 el presidente de la República y el Senado pueden obligar al Estado mexicano en cualquier materia, independientemente de que para otros efectos ésta sea competencia de las entidades federativas. Como consecuencia de lo anterior, la interpretación del artículo 133 lleva a considerar en un tercer lugar al derecho federal y al local en una misma jerarquía en virtud de lo dispuesto en el artículo 124 de la Ley Fundamental, el cual ordena que "Las facultades que no están expresamente concedidas por esta Constitución a los funcionarios federales, se entienden reservadas a los Estados". No se pierde de vista que en su anterior conformación, este Máximo Tribunal había adoptado una posición diversa en la tesis P. C/92, publicada en la Gaceta del Semanario Judicial de la Federación, Número 60, correspondiente a diciembre de 1992, página 27, de rubro: "LEYES FEDERALES Y TRATADOS INTERNACIONALES. TIENEN LA MISMA JERARQUÍA NORMATIVA."; sin embargo, este Tribunal Pleno considera oportuno abandonar tal criterio y asumir el que considera la jerarquía superior de los tratados incluso frente al derecho federal [Consulta: 29 de diciembre de 2017]. Disponible en: htps://sjf.scjn.gob.mx/SJFSist/paginas/Detalle.GeneralV2.aspx?Epoca=1e3e1fdfdf8fcfd\&tApendice=1000000000 000\&tExpresion=leyes $\% 2520$ federales $\% 2520 \mathrm{y} \% 2520$ los $\% 2520$ tratados $\% 2520$ internacionales $\% 2520 \&$ tDominio $=R$ ubro,Texto\&TA_TJ=2\&Orden $=1 \&$ Clase $=$ DetallwTesisBLEtNumTE $=101 \&$ Epp $=20 \&$ Desde $=-100 \&$ Hasta $=-$ InstanciasSel

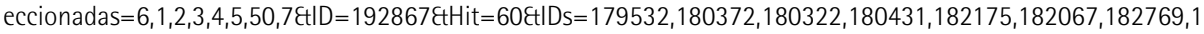
82764, 185291,186044,186264,187099,187630,187817,188899,191112,191463,192298,192757,192867\&tipoTesis $=\&$ tSemanario $=0$ Cttabla $=\&$ tReferencia $=\&$ tTema $=$ (fecha de consulta: 18 de octubre de 2015).

${ }^{30}$ Novena Época. Instancia: Pleno. Fuente: Semanario Judicial de la Federación y su Gaceta. Tomo XXV, Abril de 2007. Materia(s): Constitucional. Tesis: P. IX/2007. Página: 6 TRATADOS INTERNACIONALES. SON PARTE INTEGRANTE DE LA LEY SUPREMA DE LA UNIÓN Y SE UBICAN JERÁRQUICAMENTE POR ENCIMA DE LAS LEYES GENERALES, FEDERALES Y LOCALES. INTERPRETACIÓN DEL ARTICULO 133 CONSTITUCIONAL. La interpretación sistemática del artículo 133 de la Constitución Política de los Estados Unidos Mexicanos permite identificar la existencia de un
} 
mexicana no había establecido la posición que los tratados internacionales tenían respecto a la norma constitucional. Previo a la resolución de la jurisprudencia 293/2011, existían al menos dos posiciones claramente definidas sobre este particular.

La primera postura, con base en el artículo 133 constitucional, sostenía que la Constitución es la (única) norma suprema del ordenamiento jurídico de la que derivan su validez todas las demás, incluidas las normas sobre derechos humanos contenidas en los tratados internacionales.

Por su parte, la segunda posición establecía que los tratados internacionales se encuentran al mismo nivel de la Constitución. Quienes razonan de esta última manera afirman también que los derechos humanos reconocidos en los tratados internacionales de los que México es parte quedan ipso facto incorporados al ordenamiento jurídico a nivel constitucional por disponerlo así el propio artículo 1 de la Constitución.

La jurisprudencia número 293/2011, comúnmente denominada Proyecto Zaldívar, tenía la encomienda de resolver la contradicción existente entre el Primer Tribunal Colegiado en Materias Administrativa y de Trabajo del Décimo Primer Circuito, que sostenía en tesis aislada que los tratados o convenciones internacionales en materia de derechos humanos suscritos por el Estado mexicano deben ubicarse propiamente a nivel de la Constitución, y el Séptimo Tribunal Colegiado en Materia Civil del Primer Circuito, que colocaba a los tratados internacionales en materia de derechos humanos jerárquicamente por debajo de la Constitución.

El 3 de septiembre de 2013, el Pleno de la Corte, al resolver la contradicción planteada, determinó que los tratados internacionales se ubican jerárquicamente por encima de las leyes federales y que los tratados internacionales

\footnotetext{
orden jurídico superior, de carácter nacional, integrado por la Constitución Federal, los tratados internacionales y las leyes generales. Asimismo, a partir de dicha interpretación, armonizada con los principios de derecho internacional dispersos en el texto constitucional, así como con las normas y premisas fundamentales de esa rama del derecho, se concluye que los tratados internacionales se ubican jerárquicamente abajo de la Constitución Federal y por encima de las leyes generales, federales y locales, en la medida en que el Estado Mexicano al suscribirlos, de conformidad con lo dispuesto en la Convención de Viena Sobre el Derecho de los Tratados entre los Estados y Organizaciones Internacionales o entre Organizaciones Internacionales y, además, atendiendo al principio fundamental de derecho internacional consuetudinario "pacta sunt servanda", contrae libremente obligaciones frente a la comunidad internacional que no pueden ser desconocidas invocando normas de derecho interno y cuyo incumplimiento supone, por lo demás, una responsabilidad de carácter internacional [Consulta: 2 de enero de 2017]. Disponible en: https://sjf.scjn.gob.mx/SJFSist/paginas/DetalleGeneralV2.aspx?Epoca=1e3e1fdfdf8fcfdetApendice= 1000000000000 tExpresion=leyes $\% 2520$ federales $\% 2520 y \% 2520$ los $\% 2520$ tratados $\% 2520$ internacionales $\% 2520$ \&tDominio=Rubro,Texto\&TA_TJ=2\&Orden $=1 \&$ Clase $=$ DetalleTesisBLENumTE $=101 \& \mathrm{Epp}=20 \mathrm{EDesde}=-100 \& \mathrm{tH}$ asta $=-$ $=6,1,2,3,4,5,50,7 \& \mathrm{C}=172650 \& \mathrm{tH} i \mathrm{t}=36 \mathrm{t} \mid \mathrm{Ds}=163673,166805,167254,167598,167589,167850,168977,169118$, $169108170089,170516,170570,170880,172641,172667,172650,175559,177199,177309,179533 \& t$ tipoTesis=\&Sema nario $=0 \&$ tabla $=\&$ tReferencia $=\&$ tTema $=$.
} 
sobre derechos humanos se ubican a la par de la Constitución, pero que siempre que haya una restricción al ejercicio de un derecho humano en particular establecida por la Constitución debe estarse a lo previsto por la propia Constitución. $^{31}$

De esta forma, tratándose de los derechos humanos, el texto constitucional se ha abierto para incluir con idéntica fuerza normativa las disposiciones de fuente internacional sobre la materia. Es decir, los derechos humanos constitucionales y convencionales, al erigir un conjunto único e indivisible de derechos que se relacionan entre sí en términos de armonización y coordinación mas no de jerarquía, conforman lo que se ha denominado bloque de constitucionalidad.

El bloque de constitucional, al fungir como nuevo parámetro de validez del sistema jurídico mexicano, provoca que los órganos del Estado deban interpretar y aplicar conjuntamente los derechos humanos incluidos en la Constitución y los derechos humanos comprendidos en los tratados internacionales, pues ambos grupos de derechos -sin importar su origen normativo-, al tener jerarquía constitucional, comparten el mismo valor jurídico.

Es por ello que, de existir una colisión entre derecho interno y derecho internacional, debe mediar la ponderación y adoptarse, al amparo del principio pro persona, la interpretación más favorable al derecho humano de que se trate en relación con las dos fuentes con las que se cuenta: la constitucional y la internacional.

De acuerdo con lo expuesto, el Convenio (número 102) sobre la seguridad social (norma mínima), al cumplir con los requisitos de forma para incorporarse al ordenamiento jurídico mexicano, en particular en materia de jubilaciones, pensiones u otras formas de retiro, puesto que entró en vigor en México el 12 de octubre de 1972, se encuentra ubicado a nivel de la Constitución, por lo que sus disposiciones deberán ser observadas por todas las autoridades y sus destinatarios.

\footnotetext{
${ }^{31}$ Consideramos que la determinación del Pleno de la Corte es desafortunada porque transgrede el artículo 1 constitucional, que incorpora con rango constitucional los derechos asegurados por los tratados internacionales; además de contravenir el principio pro persona -que a partir de la reforma constitucional del 10 de junio de 2011 se constituye como la columna vertebral del derecho mexicano- y transgredir lo dispuesto en el artículo 2 de la Convención Americana sobre Derechos Humanos, ratificada por nuestro pais, que impone al Estado que se adhiere a un tratado internacional la obligación de armonizar su derecho interno con el derecho internacional, pero no al revés, como indebidamente lo considera la Corte mexicana en la contradicción de tesis 293/2011, ya que la firma de un tratado internacional le impone al Estado signatario el deber de cumplirlo, lo cual se logra mediante el reconocimiento, adopción y constitucionalización de los derechos convencionales en el derecho nacional, generando su inobservancia una responsabilidad por parte del Estado como sujeto obligado.
} 
El Convenio (número 102) sobre la seguridad social (norma mínima) adoptado en la 35 reunión de la Conferencia Internacional del Trabajo (28 de junio de 1952) - consta de quince partes. Las partes II a la X contienen disposiciones para cada una de las nueve ramas principales de la seguridad social, es decir, la asistencia médica, la enfermedad, el desempleo, la vejez, los accidentes de trabajo y enfermedades profesionales, la familia, la maternidad, la invalidez y las prestaciones de sobrevivientes. ${ }^{32}$ Las partes restantes (I y XI a $\mathrm{XV}$ ) contienen disposiciones comunes a todas las ramas.

El nivel mínimo de las prestaciones se fija en relación con el nivel de salarios del país interesado. Las exclusiones temporales están previstas en beneficio de los países cuya economía y recursos médicos no estén lo suficientemente desarrollados, por lo que las exclusiones autorizan la restricción del campo de aplicación del convenio, así como la extensión de las prestaciones garantizadas.

México ratificó en 1961 las ramas de asistencia médica, enfermedad, maternidad, vejez, accidentes de trabajo y enfermedades profesionales. En lo concerniente a las prestaciones de vejez, el convenio 102 dispone que los pagos periódicos deben, por lo menos, alcanzar 40\% del salario de referencia, y existe la obligación de revisar estos montos en caso de variaciones sensibles del nivel general de ingresos o del costo de vida. ${ }^{33}$

En el artículo 29, párrafo 2, del convenio 102 se consigna el otorgamiento y pago de una prestación de vejez reducida que ha de garantizarse como mínimo a una persona protegida que ha cumplido, antes de la contingencia, un período de calificación de quince años de cotizaciones o de empleo. ${ }^{34}$

En contraposición con esta disposición normativa, el último párrafo del artículo 162 de la actual Ley del Seguro Social dispone que el asegurado que tenga sesenta y cinco años o más y no reúna las 1250 semanas de cotización tendrá derecho a las prestaciones en especie del seguro de enfermedades y maternidad, y podrá retirar el saldo de su cuenta individual en una sola exhibición o seguir cotizando hasta cubrir las semanas requeridas para que opere el pago de la pensión de vejez.

\footnotetext{
${ }^{32}$ México ratificó el 12 de octubre de 1961 las partes II, III, V, VI y VIII-X del convenio número 102 sobre la seguridad social (norma minima).

${ }^{33}$ Convenio 102 sobre la seguridad social (norma mínima) [Consulta: 2 de enero de 2017]. Disponible en: http:// www.ilo.org/dyn/normlex/es/f?p=NORMLEXPUB:12100:0::NO::P12100_ILO_CODE:C102.

34 Idem.
} 
Dentro del mecanismo de control periódico de la aplicación de las normas internacionales del trabajo (NIT), ${ }^{35}$ basado en el examen de las memorias que presentan periódicamente los Estados miembros sobre las medidas que han adoptado para poner en ejecución los convenios de la orT que han ratificado y en las observaciones que a este respecto remiten las organizaciones de trabajadores y de empleadores, la Comisión de Expertos en Aplicación de Convenios y Recomendaciones de la OIT (CEACR) en lo referente a la pensión de vejez ha concluido lo siguiente:

la opción de retirar el saldo de su cuenta individual en una sola exhibición ante la falta de cumplimiento de los requisitos para optar por la pensión de vejez, el seguir cotizando hasta cubrir las semanas necesarias para que opere este tipo de pensión y el otorgamiento de las prestaciones en especie del seguro de enfermedades y maternidad al asegurado que hubiese cotizado 750 semanas, no son suficientes para garantizar la aplicación del artículo 29, párrafo 2, del Convenio 102 con arreglo al cual una prestación de vejez reducida ha de garantizarse como mínimo a una persona protegida que ha cumplido, antes de la contingencia, un periodo de calificación de quince años de cotizaciones o de empleo.

Ante tal situación, se ha recomendado al Gobierno mexicano realizar las acciones pertinentes para que se garantice el otorgamiento de la prestación reducida a aquellos que cumplan con los requisitos exigidos para ello, ${ }^{36}$ además de resultar necesaria la participación de los asegurados en la administración de las afores y de las Sociedades de Inversión Especializadas de Fondos para el Retiro, al igual que en las compañías de seguros, pues en el contenido de los artículos 29 y 49 de la Ley de los Sistemas de Ahorro para el Retiro no se

\footnotetext{
${ }^{35}$ Dado que la prolifica normatividad de la or se ocupa de regular aspectos referentes al campo de la seguridad social, se considera desafortunado el término de normas internacionales de trabajo, debido a que está acotado al ámbito de lo laboral, lo cual no expresa toda la gama de tópicos que son materia de regulación por parte de la organización. A nuestro entender, estimamos más loable el término normas internacionales sociales (NIS) por ser incluyente y representativo de la variedad de temas laborales y de seguridad social de los que se ocupa la organización desde su fundación, al encomendarse en el preámbulo de su texto constitucional la tarea de mejorar las condiciones de trabajo mediante la lucha contra el desempleo, la protección del trabajador contra las enfermedades, sean o no profesionales, y contra los accidentes del trabajo, las pensiones de vejez e invalidez.

${ }^{36}$ CEACR, Solicitud directa, Adopción 2007. Publicación 97a reunión CIT (2008) [Consulta: 28 de noviembre de 2017]. Disponible en: http://www.ilo.org/dyn/normlex/es/?p=1000:13101:0::fNO:13101:P13101_COMMENT_ID:3150375; CEACR Observación, Adopción 2000, Publicación 89a reunión CIT (2001) [Consulta: 3 de enero de 2018]. Disponible en: http://www.ilo.org/dyn/normlex/es/f?p=1000:13101:0::NO:13101:P13101_COMMENT_ID:3150375; CEACR, Observación, Adopción 1998, Publicación 87a reunión CIT (1999) [Consulta: 3 de enero de 2018]. Disponible en: http:// www.lo.org/dyn/normlex/es/f?p=1000:13101:0::NO:13101:P13101_COMMENT_ID:3150375.
} 
advierte que los consejeros independientes representan los intereses de los trabajadores. ${ }^{37}$

Y es que la falta de pago de las prestaciones en dinero derivadas del otorgamiento de una pensión de vejez reducida se trata de un caso de responsabilidad por omisión al imperativo jurídico internacional establecido en el artículo 29, párrafo 2, del convenio 102.

Lo anterior, de acuerdo con Jiménez Aréchaga, da lugar al surgimiento de una nueva relación entre el sujeto, al cual la omisión le es imputable y debe responder mediante una reparación adecuada y el sujeto que tiene derecho de reclamar la reparación por incumplimiento, ${ }^{38}$ al lesionarse su derecho subjetivo.

Así, de acuerdo con la doctrina, ${ }^{39} \mathrm{en}$ el caso que nos ocupa, la responsabilidad del Estado mexicano reúne como elementos constitutivos de la responsabilidad internacional los siguientes:

a. Tal como lo ha reconocido la Organización Internacional del Trabajo, se trata de una omisión imputable al Estado mexicano.

b. Existe una violación al orden jurídico internacional instaurado previamente, consistente en la transgresión al convenio 102 como norma de derecho interna e internacional vigente por disposición del artículo 1 constitucional, lo que provoca que la responsabilidad pueda ser exigida en el ámbito nacional e internacional.

c. El daño, producto de la omisión que se imputa al Estado mexicano, se trata de la violación al convenio 102, lo que provoca la privación del pago de la pensión de vejez reducida.

d. La reparación, como completo indispensable para la debida aplicación del Convenio. ${ }^{40}$

Precisamente en lo concerniente a la reparación, no sólo debe considerarse el otorgar y cubrir la pensión de vejez reducida e incrementos, sino que, bajo los lineamientos dados por la oIT, se estima necesaria la modificación del último párrafo del artículo 162 de la actual Ley del Seguro Social, para que a

\footnotetext{
${ }^{37}$ CEACR, Observación, Adopción 2013, Publicación 103a [Consulta: 28 de noviembre de 2017]. Disponible en: http://www.ilo.org/dyn/normlex/es/f?p=1000:13101:0::NO:13101:P13101_COMMENT_ID:3150375; CEACR, Observación, Adopción 2002, Publicación 91a reunión CIT (2003) [Consulta: 2 de enero de 2018]. Disponible en: http:// www.lo.org/dyn/normlex/es/f?p=1000:13101:0::NO:13101P13101_COMMENT_ID:3150375.

${ }^{38}$ Jiménez Aréchaga, Eduardo, Derecho internacional contemporáneo, Tecnos, Madrid, 1980, p. 212.

${ }^{39}$ Idem.

${ }^{40}$ Corte Permanente de Justicia Internacional, Caso Fábrica Chorzow (Alemania vs Polonia). Sentencia de 26 de julio de 1927. Fondo (Serie A), N. 13, septiembre de 1928, pp. 27-28.
} 
los asegurados que, habiendo cumplido sesenta y cinco años o más y con un mínimo de 750 semanas de cotización, los adultos mayores puedan acceder a una pensión reducida sin recurrir a las instancias nacionales e internacionales, de acuerdo con el artículo 29, párrafo 2, del convenio 102, que, al haber sido ratificado por México, forma parte del bloque de constitucionalidad por disposición del artículo 1 constitucional.

De acuerdo con el Centro Latinoamericano y Caribeño de Demografía (Celade), ${ }^{41}$ los ingresos provenientes de la seguridad social, especialmente las jubilaciones y pensiones, pueden convertirse en el único sustento de las personas durante el último tercio de sus vidas, ${ }^{42}$ debido a que la mayoría de los adultos mayores dejan de producir ingresos o no se producen de la misma forma en que acontecía durante la juventud ante las limitaciones comunes de esta etapa de la vida o por la exclusión del sistema económico que, con frecuencia, ellos padecen ante las escasas oportunidades que oferta el mundo laboral.

Tan sólo en el primer trimestre de 2017, la tasa de participación económica de la población de sesenta y más años fue de 33.9\%. ${ }^{43}$ Por edad, esta tasa es 3.5 veces mayor en la población de 60 a 64 años, por lo que se ubicó en 49.6\%; en tanto que en la población de 75 años en adelante representó el 14.3\%. Cabe señalar que el porcentaje de la población de sesenta y más años que no es económicamente activa fue de $66.1 \%$, y de estos, 54\% se encontraba dedicado a los quehaceres del hogar, en los que no existe retribución alguna. ${ }^{44}$

Dos aspectos que se distinguen de la población ocupada que tiene sesenta y más años (4.8 millones), es que prácticamente del 49\% que labora por cuenta, el $4.4 \%$ no percibe remuneración alguna por su trabajo. ${ }^{45}$

Por su parte, del 37.8\% de los adultos mayores que se ocupan de manera subordinada, 60.8\% no tiene acceso a instituciones de salud por su trabajo; $61.8 \%$ labora sin tener un contrato de trabajo formal y $47.7 \%$ no percibe ningún tipo de prestación. ${ }^{46}$ De hecho, $73.2 \%$ de los adultos mayores laboran

\footnotetext{
${ }^{41}$ Desde 1997 el Centro Latinoamericano y Caribeño de Demografia (Celade) es la División de Población de la Comisión Económica para América Latina y el Caribe (CEPAL),

${ }^{42}$ Comisión Económica para América Latina y el Caribe-Centro Latinoamericano y Caribeño de Demografía, Informe de actividades 2006-2008 sobre envejecimiento y desarrollo para el Comité Especial sobre Población y Desarrollo del periodo de sesiones de la CEPAL. DDR/2, Santo Domingo, 2008, p. 12.

${ }^{43}$ Instituto Nacional de Estadistica, Geografía e Informática, Estadísticas a propósito del día internacional de las personas de edad. Datos nacionales [Consulta: 3 de enero de 2018]. Disponible en: http://www.inegi.org.mx/saladeprensa/aproposito/2017/edad2017_Nal.pdf.

44 Idem.

${ }^{45}$ Idem.

${ }_{46}$ Idem.
} 
de manera informal, ${ }^{47}$ lo que trae aparejada la evasión del pago de las cotizaciones de seguridad social y la falta de pago de los beneficios previstos en las leyes de seguros sociales.

La tasa de participación económica en los adultos mayores con discapacidad en 2017 representó 24.2\%, y en aquellos que presentan alguna limitación fue del 38.3\%. De la población ocupada de sesenta y más años con discapacidad, 56.4\% se encontraba laborando de manera independiente; 18.1\% era empleada y 13.7\% no recibía contraprestación alguna. Mientras que de la población que presenta alguna limitación, 52.9\% prestó sus servicios de forma independiente, $22.6 \%$ era empleada y $11 \%$ prestó sus servicios sin recibir ninguna remuneración. ${ }^{48}$

Otro aspecto que vulnera a las personas de edad es no tener un apoyo al interior del hogar. En 2017 en México existían 1.6 millones de personas de sesenta y más años que vivían solas. ${ }^{49}$ Ante estas cifras, los sistemas de pensiones constituyen una de las formas básicas sobre las que se ha construido la seguridad de los ingresos de los adultos mayores, cuyo papel es además preponderante en el combate de la pobreza.

En México, conforme a los datos de la Encuesta Nacional de Empleo y Seguridad Social levantada en 2013, una cuarta parte (26.1\%) de los adultos mayores se encontraba pensionada. De estos, 40.9\%, por jubilación; 33.9\%, por retiro o vejez; 17.5\%, por viudez, y 3.6\%, por riesgos de trabajo, lo que representa un porcentaje mínimo que inobserva el principio de universalidad de la seguridad social.

Si bien es cierto que el establecimiento de pisos de protección social ${ }^{50}$ y la pensión universal para adultos mayores son dos de los mecanismos deseables

\footnotetext{
47 Idem.

48 Idem.

49 ldem.

${ }^{50}$ El Piso de Protección Social (Pps) es un concepto coherente de política social cuyo objetivo es garantizar que todas las personas necesitadas tengan acceso a una atención de salud esencial y a una seguridad básica del ingreso que aseguren conjuntamente un acceso efectivo a los bienes y servicios definidos como necesarios a nivel nacional. Véase OIT, ¿Porqué necesitamos una recomendación sobre Pisos de Protección Social? [Consulta: 2 de enero de 2018]. Disponible en: http://www.ilo.org/global/about-the-ilo/newsroom/news/WCMS_182276/lang--es/index. htm. Conforme a la recomendación número 202, los PPS deberán comprender por lo menos como garantías básicas de seguridad social el acceso a la atención de salud esencial, incluida la atención de la maternidad; la seguridad básica del ingreso para los niños, que asegure el acceso a la alimentación, la educación, los cuidados y cualesquiera otros bienes y servicios necesarios; la seguridad básica del ingreso para las personas en edad activa que no puedan obtener ingresos suficientes, en particular en caso de enfermedad, desempleo, maternidad e invalidez, y la seguridad básica del ingreso para las personas de edad avanzada.
} 
para asegurar los ingresos en la vejez, no han sido implementados por la mayoría de los países. ${ }^{51}$

En nuestro país resulta complicado cotizar al régimen obligatorio del seguro social de manera continua y prolongada para poder acceder a una pensión completa que asegure una vejez con los mínimos satisfactores, debido a la precariedad de las relaciones laborales, la presencia de contratos por tiempo u obra determinada o el fraude de los contratos laborales por honorarios.

A lo anterior se adiciona el incremento del trabajo informal, dentro del cual el Instituto Nacional de Estadística y Geografía ubica al trabajo no protegido en la actividad agropecuaria, ${ }^{52}$ el servicio doméstico remunerado de los hogares, así como los trabajadores subordinados que, aunque lo hacen para unidades económicas formales, laboran bajo modalidades en las que se elude el registro ante la seguridad social.

De acuerdo con los resultados de la Encuesta Nacional de Ocupación y Empleo (ENOE) para el trimestre enero-marzo de 2017, todas las modalidades de empleo informal sumaron 29.7 millones de personas, lo que representó $57.2 \%$ de la población ocupada. ${ }^{53}$ Concretamente, la ENOE indicó que 14.2 millones conformaron la ocupación en el sector informal, lo que constituyó 27.3\% de la Tasa de Ocupación en el Sector Informal, cuya distribución fue la siguiente: 7.4 millones corresponden al ámbito de las empresas, gobierno e instituciones; 5.8 millones al agropecuario, y 2.3 millones al servicio doméstico remunerado. ${ }^{54}$

Sin olvidar que la escasez de recursos no exime a los Estados de ciertas obligaciones mínimas esenciales en la aplicación de los derechos económicos, sociales y culturales, ${ }^{55}$ en México es necesario que, en cumplimiento al artículo 29, párrafo 2 , del convenio 102, se regule el pago de una pensión

\footnotetext{
${ }^{51}$ Tanto en Canadá como en Estados Unidos la cobertura de las pensiones de vejez es universal. En Aruba, Argentina, Bolivia (Estado Plurinacional de), Guyana y Trinidad y Tobago, la cobertura alcanza el 100\%, y los adultos mayores perciben prestaciones monetarias periódicas. Vid. Organización Internacional del Trabajo, Informe mundial sobre la protección social 2017-2019. La protección social universal para alcanzar los Objetivos de Desarrollo Sostenible, OIT, Ginebra, 2017, p. 150.

${ }^{52} \mathrm{El}$ aumento anual en el empleo fue impulsado principalmente por el sector agropecuario, con un crecimiento de $5.7 \%$.

${ }^{53}$ Instituto Nacional de Estadistica, Geografia e Informática, Encuesta Nacional de Ocupación y Empleo (ENOE), enero-marzo de 2017 [Consulta: 3 de enero de 2018]. Disponible en: http://www.inegi.org.mx/saladeprensa/boletines/2017/enoe_ie/enoe_ie2017_05.pdf.

54 Idem.

${ }^{55}$ Directriz 10 de las Directrices de Maastricht sobre Violaciones a los Derechos Económicos, Sociales y Culturales Maastricht, 22-26 de enero de 1997 [Consulta: 29 de noviembre de 2017]. Disponible en: http://www.derechoshumanos.un/p.edu.ar/assets/files/documentos/directrices-de-maastricht-sobre-violaciones-a-los-derechos-economicos-sociales-y-culturales.pdf.
} 
reducida de vejez que sea proporcional al salario de cotización, a la edad de retiro y a las aportaciones realizadas por el asegurado, el empleador y el Estado en el seguro de retiro, cesantía en edad avanzada y vejez, en términos del artículo 168 de la Ley del Seguro Social, que regula el financiamiento de este rama del seguro social.

El acceso asequible y proporcional a las prestaciones en dinero del seguro de vejez, como resultado de las aportaciones tripartitas efectuadas en la cuenta individual al cumplimentar lo dispuesto por el convenio número 102, soslayando una posible responsabilidad internacional por parte de México, permitirá que un mayor número de adultos mayores tenga una estabilidad e independencia económica, evitando caer en una situación de pobreza.

También, hay que destacar el gasto que los integrantes del hogar realizan en salud. De acuerdo con los datos de la Encuesta Nacional de Ingresos y Gastos de los Hogares, de 2016, en poco más de la mitad de los hogares donde había un adulto mayor se realizó un gasto equivalente 53.7\%, que comprendía la atención ambulatoria, hospitalaria o farmacéutica. ${ }^{56}$

En 2016, para la población adulta mayor las enfermedades del sistema circulatorio representaron 32.5\%; las enfermedades endocrinas, nutricionales y metabólicas se ubicaron en 20.1\%; los tumores, 13.1\%; las enfermedades del sistema respiratorio, 10.7\%; y las enfermedades del sistema digestivo, $9.1 \%$, por lo que representan las principales causas de muerte entre la población de sesenta y más años. ${ }^{57}$

Estas últimas cifras evidencian que los adultos mayores, al ser un grupo en el cual las enfermedades generales se hacen presentes de manera cotidiana, la derechohabiencia en los organismos de seguridad social resulta ser un beneficio de gran ayuda para las familias.

Es necesario que el Instituto Mexicano del Seguro Social brinde servicios médicos especializados en geriatría y gerontología, con el fin de garantizar la cobertura de los servicios de salud requeridos por la población adulta mayor. No debemos olvidar que si durante su vida laboral la mayoría de las personas aportan su capacidad productiva y contribuyen al desarrollo y progreso de su país, justo es que al envejecer tengan una vida digna y de calidad en sus dos vertientes.

En su vertiente teórica, el concepto de calidad de vida debe incluir las especificidades propias de la vejez, tanto fisiológica como social, y considerar

\footnotetext{
${ }^{56}$ Instituto Nacional de Estadistica, Geografia e Informática, op. cit., nota 53.

${ }^{57}$ Idem.
} 
las diferencias respecto a las anteriores etapas del ciclo de vida. A ello se suma que hay que identificar los elementos de naturaleza objetiva (redes de apoyo, servicios sociales, condiciones económicas, entorno, etc.) y subjetiva (salud, satisfacción, etc.) intervinientes. ${ }^{58}$

En su vertiente práctica, los desafíos en relación con la calidad de vida en la vejez que se identifican son: ${ }^{59}$

- A nivel de mercado, el aumento del número absoluto y relativo de personas mayores provoca modificaciones tanto en el mercado del trabajo como en el de bienes y servicios.

- A nivel de sociedad, genera nuevas formas de organización de la familia, así como diversas respuestas de la comunidad a los nacientes desafíos de bienestar.

- A nivel de Estado, se debe hacer frente a las nuevas tensiones sociales surgidas de las necesidades de financiamiento de los sistemas de seguridad social, a los cambios en las relaciones de dependencia económica entre generaciones y a la competencia intergeneracional por los puestos de trabajo.

\section{Conclusiones}

Es necesario garantizar los derechos de los adultos mayores a través de mecanismos idóneos, eficaces y accesibles a este tipo de población, evitando que los convenios y las recomendaciones suscritas en su favor se conviertan en un conjunto de buenos deseos.

En el ámbito de la seguridad social, ante el nuevo modelo de capitalización individual que impera en la Ley del Seguro Social con un importante incremento en el número de semanas que deben cotizar los derechohabientes del IMSS para acceder a una pensión de vejez, pues de las quinientas cotizaciones requeridas conforme a la Ley del Seguro Social del 12 de marzo de 1973 se eleva el número a 1250 en el actual ordenamiento, la pensión de vejez reducida constituye un derecho que, de acuerdo con el párrafo 2 del artículo 29 del Convenio 102, debe ser cubierto a los adultos mayores que cotizaron un

\footnotetext{
${ }^{58}$ Huenchuan Navarro, Sandra, Marco legal y de politicas en favor de las personas mayores en América Latina. Proyecto Implementation of the Madrid Plan of Action on Ageing and the Regional Conference on Ageing, Centro Latinoamericano y Caribeño de Demografía, Santiago de Chile, 2004, p. 26.

${ }^{59} / \mathrm{dem}$.
} 
mínimo de 750 semanas, en aras de contribuir a disminuir la vulnerabilidad de esta población y elevar su calidad de vida.

Sin importar la situación económica del IMSS, la pensión por vejez reducida no constituye un derecho de papel ni una dádiva gubernamental sujeta a la disponibilidad de recursos económicos, sino un auténtico derecho subjetivo financiado por el asegurado durante más de catorce años.

\section{ReFERENCIAS}

Fix-Zamudio, Héctor, "Las repercusiones en los ámbitos interno e internacional de la reforma constitucional mexicana sobre derechos humanos del 10 de junio de 2011", en Serna de la Garza, José Ma. (coord.), Contribuciones al derecho constitucional (coord.), UNAM-Instituto de Investigaciones Jurídicas, México, 2016.

Ferrer Mac-Gregor, Eduardo, "Interpretación conforme y control difuso de convencionalidad. El nuevo paradigma para el juez mexicano", Estudios Constitucionales, año 9, núm. 2, 2011.

Jiménez Aréchaga, Eduardo, Derecho internacional contemporáneo, Tecnos, Madrid, 1980.

Huenchuan Navarro, Sandra, Marco legal y de politicas en favor de las personas mayores en América Latina. Proyecto Implementation of the Madrid Plan of Action on Ageing and the Regional Conference on Ageing, Centro Latinoamericano y Caribeño de Demografía, Santiago de Chile, 2004.

Organización Internacional del Trabajo, Informe mundial sobre la protección social 2017-2019. La protección social universal para alcanzar los Objetivos de Desarrollo Sostenible, OIT, Ginebra, 2017.

, ¿Porqué necesitamos una recomendación sobre Pisos de Protección Social? [Consulta: 2 de enero de 2018]. Disponible en: http://www. ilo.org/global/about-the-ilo/newsroom/news/WCMS_182276/lang--es/ index.htm.

Constitución Política de los Estados Unidos Mexicanos [Consulta: 29 de diciembre de 2017]. Disponible en: http://www.diputados.gob.mx/LeyesBiblio/ pdf/1_150917.pdf.

Declaración Americana de los Derechos y Deberes del Hombre [Consulta: 31 de diciembre de 2018]. Disponible en: https://www.oas.org/dil/esp/ Declaraci\%C3\%B3n_Americana_de_los_Derechos_y_Deberes_del_ Hombre_1948.pdf.

Declaración Universal de Derechos Humanos [Consulta: 29 de septiembre de 2017]. Disponible en: http://www.ordenjuridico.gob.mx/TratInt/Derechos\%20 Humanos/INST\%2000.pdf.

Protocolo Adicional a la Convención Americana sobre Derechos Humanos en mate- 
ria de Derechos Económicos, Sociales y Culturales [Consulta: 2 de enero de 2018]. Disponible en: http://www.ordenjuridico.gob.mx/TratInt/Derechos\%20Humanos/PI2.pdf.

Constitución de la Organización Internacional del Trabajo [Consulta: 6 de enero de 2017]. Disponible en: http://www.ilo.org/dyn/normlex/es/ $f ? p=1000: 62: 0::$ N0:62:P62_LIST_ENTRIE_ID:2453907:NO\#A14.

Pacto Internacional de Derechos Económicos, Sociales y Culturales [Consulta: 29 de octubre de 2017]. Disponible en: http://www.ohchr.org/SP/ProfessionaIInterest/Pages/CESCR.aspx.

Convención sobre la Eliminación de todas las Formas de Discriminación contra la Mujer [Consulta: 21 de octubre de 2017]. Disponible en: http://www.ohchr.org/SP/ProfessionalInterest/Pages/CEDAW.aspx.

Convenio 102 sobre la seguridad social (norma mínima) [Consulta: 2 de enero de 2017]. Disponible en: http://www.ilo.org/dyn/normlex/es/f?p=NORMLE XPUB:12100:0::NO::P12100_ILO_CODE:C102.

Ley del Seguro Social [Consulta: $1^{\circ}$ de enero de 2018]. Disponible en: http://www. diputados.gob.mx/LeyesBiblio/pdf/92_121115.pdf.

Ley de los Derechos de las Personas Adultas Mayores [Consulta: 24 de noviembre de 2017]. Disponible en: http://www.salud.gob.mx/unidades/cdi/nom/compi/ldpam.html.

Ley Federal del Trabajo [Consulta: $1^{\circ}$ de enero de 2018]. Disponible en: http://www. diputados.gob.mx/LeyesBiblio/pdf/125_120615.pdf.

Reglamento de la Ley del Seguro Social en materia de afiliación, clasificación de empresas, recaudación y fiscalización [Consulta: 29 de abril de 2014]. Disponible en: http://www.diputados.gob.mx/LeyesBiblio/regley/Reg_ LSS_MACERF.pdf.

Declaración Política y Plan de Acción Internacional de Madrid sobre el Envejecimiento [Consulta: 29 de noviembre de 2017]. Disponible en: https://social.un.org/ageing-working-group/documents/mipaa-sp.pdf.

Declaración sobre el Progreso y el Desarrollo en lo Social, [Consulta: 2 de enero de 2018] Disponible en: http://www.ohchr.org/SP/ProfessionalInterest/Pages/ProgressAndDevelopment.aspx.

Directrices de Maastricht sobre Violaciones a los Derechos Económicos, Sociales y Culturales Maastricht, 22-26 de enero de 1997 [Consulta: 29 de noviembre de 2017]. Disponible en: http://www.derechoshumanos.unlp.edu. ar/ assets/files/documentos/directrices-de-maastricht-sobre-violaciones-alos-derechos-economicos-sociales-y-culturales.pdf.

Plan de Acción Internacional de Viena sobre el envejecimiento de 1982. [Consulta: 29 de noviembre de 2017] Disponible en: http://www.mayoressaludables. org/sites/default/files/201703/plan_de_accion_internacional_de_viena_ sobre_el_envejecimiento.pdf.

Proclamación de Teherán. Adopción: Conferencia Internacional de Derechos Huma- 
nos, Teherán, Irán, 13 de mayo de 1968 [Consulta: 26 de octubre de 2017]. Disponible en: http://www.ordenjuridico.gob.mx/TratInt/Derechos\%20 Humanos/OTROS\%2016.pdf.

Programa Iberoamericano de Cooperación sobre Adultos Mayores. [Consulta: 29 de noviembre de 2017] Disponible en: http://www.oiss.org/IMG/pdf/ADULTOS_MAYORES_documento_aprobado_XXI_CUMBRE-2.pdf.

Recomendación sobre los trabajadores de edad (número 162) [Consulta: 6 de enero de 2017]. Disponible en: http://www.ilo.org/dyn/normlex/es/f?p= NORMLEXPUB:12100:0:: NO::P12100_ILO_CODE:R162.

Resolución relativa a la seguridad social. [Consulta: 6 de enero de 2017] Disponible en: http://white.lim.ilo.org/ssos/documentos/seguridadsocial-un-nuevo-consenso.pdf.

Resolución de la Asamblea Mundial de Naciones Unidas sobre el Envejecimiento. [Consulta: 29 de noviembre de 2017] Disponible en: https://documents-dds-ny.un.org/doc/UND0C/LTD/N02/324/66/PDF/N0232466. pdf?OpenElement.

Observaciones Generales números 6, 19 y 20 del Comité de Derechos Económicos, Sociales y Culturales [Consulta: 29 de noviembre de 2017]. Disponible en: https://conf- dts1.unog.ch/1\%20spa/tradutek/derechos_hum_base/ cescr/00_1_obs_grales_cte\%20dchos\%20ec\%20soc\%20cult.h̄tml.

Asamblea General de la Organización de Naciones Unidas, Resolución 32/131, 16 de diciembre de 1977, "Cuestión de las personas de edad y los ancianos" [Consulta: 2 de enero de 2018]. Disponible en: http://www.un.org/es/comun/docs/?symbol=A/RES/32/131 \&tLang=S.

---, Resolución 3137 (XXVIII), 14 de diciembre de 1973 "Cuestión de las personas de edad y lo ancianos". [Consulta: 2 de enero de 2018] Disponible en:http://www.un.org/es/comun/docs/?symbol=A/ RES/3137(XXVIII)\&Lang=S\&Area=R.

, Resolución 3138 (XXVIII) 14 de diciembre de 1973. "Seguridad social paralosancianos”[Consulta:2 deenerode2018].Disponibleen:http://www. un.org/es/comun/docs/?symbol=A/RES/3138(XXVIII)\&LLang=SEtArea=R.

Caso Estados Unidos, párrafos 15-16 [Consulta: 21 de diciembre de 2017], Disponible en: https://www.cidh.oas.org/annualrep/80.81sp/Estados Unidos2141a. htm.

Comisión de Expertos en Aplicación de Convenios y Recomendaciones de la OIT, Solicitud directa, Adopción 2007. Publicación 97a reunión CIT (2008) [Consulta: 28 de noviembre de 2017]. Disponible en: http://www.ilo. org/dyn/normlex/es/?p=1000:13101:0::fNO:13101:P13101_COMMENT ID:3150375.

(2001) [Consulta: 3 de enero de 2018]. Disponible en: http://www.ilo. org/dyn/normlex/es/f?p=1000:13101:0::NO:13101:P13101_COMMENT_ ID:3150375. 
, Observación, Adopción 1998, Publicación 87a reunión CIT (1999) [Consulta: 3 de enero de 2018]. Disponible en: http://www.ilo. org/dyn/normlex/es/f?p=1000:13101:0::NO:13101:P13101_COMMENT_ ID:3150375.

Observación, Adopción 2013, Publicación 103a [Consulta: 28 de noviembre de 2017]. Disponible en: http://www.ilo.org/dyn/normlex/ es/f?p=1000:13101:0::N0:13101:P13101_COMMENT_ID:3150375.

------------------, Observación, Adopción 2002, Publicación 91a reunión CIT (2003) [Consulta: 2 de enero de 2018]. Disponible en: http://www.ilo. org/dyn/normlex/es/f?p=1000:13101:0::NO:13101P13101_COMMENT_ ID:3150375.

Instituto Nacional de Estadística y Geografía, Encuesta Nacional de Ocupación y Empleo (ENOE), enero-marzo de 2017 [Consulta: 3 de enero de 2018]. Disponible en: http://www.inegi.org.mx/saladeprensa/boletines/2017/ enoe_/ ie2017_05.pdf. 